ISSN 0103-8478

\title{
Sistemas de culturas com milho sob semeadura direta na região Nordeste do Brasil
}

\author{
Maize - based cropping systems under no tillage in the Northeast of Brazil
}

\author{
Richardson Soares de Souza Melo ${ }^{\mathrm{I}}$ Antonio Sousa Silva ${ }^{\mathrm{II}}$ Ivandro de França da Silva ${ }^{\mathrm{III}}$ \\ Mayara Andrade Souza ${ }^{\mathrm{IV}}$ Luís de França da Silva Neto ${ }^{\mathrm{V}}$
}

\section{RESUMO}

A grande dificuldade de implantação da semeadura direta no Nordeste é a produção e o acúmulo de fitomassa na superfície do solo. Há necessidade de se desenvolver sistemas de culturas para região Nordeste, que produzam grandes quantidades de fitomassa, para permanecer por maior tempo na superfície, oferecendo proteção ao solo. O presente trabalho objetivou avaliar a capacidade de produção de fitomassa de diferentes sistemas de culturas e sua influencia na produtividade do milho na microrregião de Guarabira - PB. Foram instalados seis sistemas de culturas: semeadura direta com milho (SD); semeadura direta com milho + mисипа (SDM); semeadura direta com milho + guandu (SDG); semeadura direta com milho + guandu + mucuna (SDGM); semeadura direta com milho + fava (SDF) e semeadura direta com milho + fava + mucuna (SDFM), na presença e ausência de adubação mineral com N-P-K, avaliados durante 9 anos. Foram avaliados o percentual de cobertura e a quantidade de fitomassa sobre o solo, bem como a produtividade de grãos de milho. A adubação mineral e as leguminosas proporcionaram acréscimos variando entre $22 \%$ e $49 \%$ de produtividade de grãos de milho entre os sistemas de cultivo. Com o passar dos anos, os sistemas de culturas promoveram estoque de fitomassa com acréscimos de até $76 \%$ na superfície do solo e, embora a precipitação seja um fator limitante para produção de fitomassa, o uso das leguminosas e da adubação mineral com $N$-P-K nos sistemas de culturas facilitaram a implantação do sistema de semeadura direta na região estudada.

Palavras-chave: produtividade, leguminosas, milho.

\section{ABSTRACT}

The major problem of implementation of direct seeding in the Northeast is the phytomass production and accumulation on the soil surface. There is a necessity to develop cropping systems for the Northeast region, which produce large quantities of phytomass, to stay for longer time on the soil surface, providing protection to the soil. This study aimed to evaluate the ability of phytomass production of different cropping systems and its influence on corn yield in the microregion of Guarabira - PB. Six cropping systems were installed: tillage with maize (SD); tillage with corn+velvetbean (SDM); tillage with maize+pigeonpea $(S D G)$; tillage with corn+ velvetbean+pigeonpea (SDGM); tillage with corn+broad bean (SDF); and no tillage with corn+ velvetbean+broad bean (SDFM); with and without NPK fertilizer, were evaluated for 9 years. The percentage of crop cover and the phytomass accumulation on the soil and yield of corn were evaluated. The mineral fertilizer and legumes provided increases ranging between $22 \%$ and $49 \%$ of corn grain yield among tillage systems. Over the years, crop systems promoted stock biomass with increases of up to $76 \%$ on the soil surface, and although the precipitation is a limiting factor for biomass production, the use of legumes and fertilization with NPK mineral systems cultures facilitated the implementation of no-till system in this region.

Key words: productivity, pulses, maize.

\section{INTRODUÇÃO}

Em sua grande maioria, sistemas de manejo que adotam o revolvimento do solo de forma intensiva e continuada propiciam baixas taxas de adição de resíduos orgânicos e mineralização acelerada do carbono (C), o que, segundo BAYER et al. (2000), contribui para a degradação da estrutura e, consequentemente de todo o sistema solo. Por outro

IPrograma de Pós-graduação em Ciência do Solo (PPGCS), Centro de Ciências Agrárias (CCA), Universidade Federal da Paraíba (UFPB), 58051-900, Areia, PB, Brasil.E-mail: richardsonsoares@hotmail.com. Autor para correspondência.

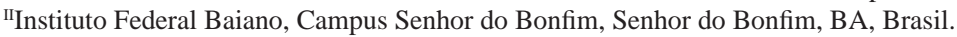

IIIDepartamento de Solos e Engenharia Rural (DSER), CCA, UFPB, Areia, PB, Brasil.



vEmbrapa Solos, Rio de Janeiro, RJ, Brasil. 
lado, a semeadura direta protege o solo contra erosão, acrescenta $\mathrm{C}$ ao sistema e promove uma melhoria na qualidade química do solo (SIQUEIRA NETO et al., 2009; PAVINATO et al., 2009). Dependendo da sequência bem planejada de culturas, as propriedades química, física e biológica do solo podem ser recuperadas através do sistema de semeadura direta (PAVINATO et al., 2009; CUNHA et al., 2011b). Nesse sentido, o manejo dos restos culturais após a colheita é um fator importante na ciclagem de nutrientes e na proteção do solo contra os efeitos climáticos e na proteção contra o processo erosivo.

Entretanto, a forma de agricultura praticada na região Nordeste não inclui o uso de corretivos e fertilizantes, ficando a produtividade das culturas dependente da fertilidade natural dos solos. Isso por sua vez tem deixado os solos erodidos, pobres em nutrientes e com baixos teores de C (FRAGA, 2002). A implantação do sistema de semeadura direta nessa região visa contornar os problemas de degradação e melhorar a produtividade das culturas. SILVA et al. (2011), comparando o sistema convencional de cultivo com a semeadura direta, perceberam, ao final de 7 anos, que a produtividade do milho foi maior no sistema conservacionista. Ainda informam que a semeadura direta apresenta-se como alternativa merecedora de estudos para a região Nordeste.

Todavia, a dificuldade de implantação da semeadura direta no Nordeste é a produção e o acúmulo de fitomassa na superfície do solo. Primeiro, por que toda fitomassa é produzida em um só período chuvoso, que dura entre três a cinco meses do ano. Segundo, como as temperaturas são sempre elevadas, as chuvas aceleram a taxa de decomposição. Assim, existe a necessidade de encontrar sistemas de culturas adaptadas às condições do Nordeste, isto é, que possam produzir grandes quantidades de material vegetal, permanecendo por maior tempo na superfície, oferecendo maior proteção ao solo (SILVA NETO, 2003; NUNES et al., 2010). Além disso, para aumentar a quantidade de fitomassa produzida, é necessário cultivar plantas de cobertura de forma intercalada, no mesmo período da cultura principal, para incrementar mais fitomassa no sistema de cultivo (SILVA NETO, 2003).

Além disso, a qualidade das plantas de cobertura deve inferir benefícios ao sistema. Trabalhando com diferentes sistemas de cultivo, BAYER et al. (2000) perceberam que uma sucessão, envolvendo gramíneas e leguminosas, favoreceu o aumento de matéria orgânica e nitrogênio ao solo e o acúmulo de fitomassa na superfície.
Diante o exposto, o presente trabalho teve como objetivo avaliar a capacidade de produção de fitomassa de diferentes sistemas de culturas e como os sistemas influenciam na cobertura do solo e na produtividade do milho na microrregião de Guarabira - PB.

\section{MATERIAL E MÉTODOS}

O experimento foi conduzido na Estação Experimental da Empresa Estadual de Pesquisa Agropecuária da Paraíba (EMEPA-PB), no município de Alagoinha - PB, microrregião de Guarabira, cujo clima, de acordo com a classificação de Köppen, é do tipo As' (quente e úmido, com chuvas no período de outono-inverno), com precipitação pluvial média anual de $1.100 \mathrm{~mm}$, em solo classificado como Nitossolo Vermelho (EMBRAPA, 2006), textura argilosa, relevo suave ondulado, cujas características iniciais de fertilidade foram: $\mathrm{pH}=5,85$; matéria orgânica=17,15g dm $\mathrm{dm}^{-3}$; fósforo=2,79mg $\mathrm{dm}^{-3}$; potássio $=27,35 \mathrm{mg} \mathrm{dm}^{-3}$ e cálcio + magnésio $=9,3 \mathrm{cmol}_{\mathrm{c}}$ $\mathrm{dm}^{-3}$.

Os sistemas foram instalados em março de 2000, com as seguintes configurações: semeadura direta com milho (SD); semeadura direta com milho + mucuna (SDM); semeadura direta com milho + guandu (SDG); semeadura direta com milho + guandu + mucuna (SDGM); semeadura direta com milho + fava (SDF) e semeadura direta com milho + fava + mucuna (SDFM). Os seis sistemas foram conduzidos na presença e ausência de adubação mineral com $\mathrm{NPK}$, sendo $90 \mathrm{~kg}$ de $\mathrm{N} \mathrm{ha}^{-1}$ (sulfato de amônio), $60 \mathrm{~kg}$ de $\mathrm{P}_{2} \mathrm{O}_{5}$ ha $^{-1}$ e $45 \mathrm{~kg} \mathrm{deK}_{2} \mathrm{O}$ ha $^{-1}$, aplicados nos sulcos de plantio do milho. A adubação nitrogenada foi parcelada, sendo aplicados $30 \mathrm{~kg} \mathrm{ha}^{-1}$ no plantio e $60 \mathrm{~kg} \mathrm{ha}^{-1}$ em cobertura.

O espaçamento utilizado para o milho (Zea mays) foi de $1,00 \mathrm{~m}$ entre fileiras $\mathrm{x} 0,20 \mathrm{~m}$ entre plantas (50.000 plantas ha ${ }^{-1}$ ). O feijão guandu (Cajanus flavus) foi semeado em covas espaçadas de $0,50 \mathrm{~m}$, com duas plantas por cova (20.000 plantas ha ${ }^{-1}$ ) de forma alternada entre fileiras de milho, a fava (Vicia faba) foi semeada nas covas de milho, com duas plantas por cova, distanciadas de 1,0 na fileira e em fileiras alternadas (10.000 plantas ha-1), e a mucuna preta (Stizolobium aterrimum) foi plantada em covas espaçadas de $0,5 \mathrm{~m}$ entre as fileiras do milho, com três plantas por cova (60.000 plantas ha-1). O milho, o guandú e a fava foram plantados no mesmo dia e a mucuna preta, oitenta e cinco dias após o plantio do milho. A partir do segundo ano, as plantas de cobertura do solo, antes do plantio do milho, eram 
cortadas e distribuídas sobre a superfície do solo. A área experimental foi constituída por 3 blocos com dimensões de $15,0 \mathrm{~m}$ de comprimento por $16,0 \mathrm{~m}$ de largura, com 12 parcelas de 5,0x4,0m e área útil de $8 \mathrm{~m}^{2}$, totalizando 36 unidades experimentais.

A avaliação de cobertura do solo era realizada antes do plantio em cada ano agrícola, sendo o percentual de cobertura avaliado nos anos de 2003 a 2008. A metodologia da transecção linear foi realizada utilizando-se uma corda com 5,0m de comprimento, marcada com 25 pontos, espaçados a cada $0,20 \mathrm{~m}$, na qual se efetuou a contagem dos pontos visualizados sobre solo descoberto por palhada, em quatro posições diferentes sobre a parcela experimental (SLONEKER e MOLDENHAUER, 1977). A quantidade de fitomassa seca, em Mg ha-1, foi medida de 2006 a 2008. Para avaliar fitomassa seca da parte aérea, eram coletadas amostras da cobertura vegetal do solo, antes do ínício do plantio das culturas, utilizando-se um quadrado de ferro medindo $0,5 \times 0,5 \mathrm{~m}\left(0,25 \mathrm{~m}^{2}\right)$, lançado ao acaso sobre a parcela, em três repetições por parcela. Em seguida, foram colocadas em estufa a $65^{\circ} \mathrm{C}$ até atingir massa constante e após foram pesadas.

A avaliação da produtividade da cultura do milho foi realizada através da quantificação do rendimento de grãos em $\mathrm{Mg} \mathrm{ha}^{-1}$, durante os 9 anos de experimento (2000 a 2008). Depois de colhidas, as espigas foram debulhadas para retirada dos grãos. Amostras desses grãos foram colocados em estufa para determinação do teor de umidade e o peso final da produtividade foi corrigido para $12 \%$ de umidade.

O delineamento experimental foi em blocos ao acaso, num esquema fatorial triplo, sendo 6x9x2 para produtividade, 6x6x2 para cobertura e $6 \times 3 \times 2$ para fitomassa. $\mathrm{O}$ primeiro número corresponde aos sistemas de cultivo, o segundo aos anos de avaliação e o terceiro à presença e ausência de adubação. A análise estatística foi realizada utilizando o programa SAS. Quando houve diferenças, as médias foram comparadas pelo teste de Tukey.

\section{RESULTADOS E DISCUSSÃO}

Na figura 1, pode ser observado o percentual de cobertura em função da precipitação. De maneira geral, os seis sistemas de cultivo favorecem a cobertura do solo, sendo que esses percentuais são notadamente influenciados pela precipitação dos anos que antecedem a avaliação. Nota-se ainda que o percentual de cobertura do solo foi aumentando até o terceiro ano de experimento, sendo 2005 o ano com maior percentual de cobertura. Esse incremento ocorreu devido ao bom volume de precipitação do ano anterior (2004), implicando um bom desenvolvimento das leguminosas e do milho, que permitiu maior acúmulo de fitomassa. SILVA et al. (2011) também observaram um maior aporte de resíduos culturais na superfície do solo em anos com melhor distribuição das precipitações. Torna-se

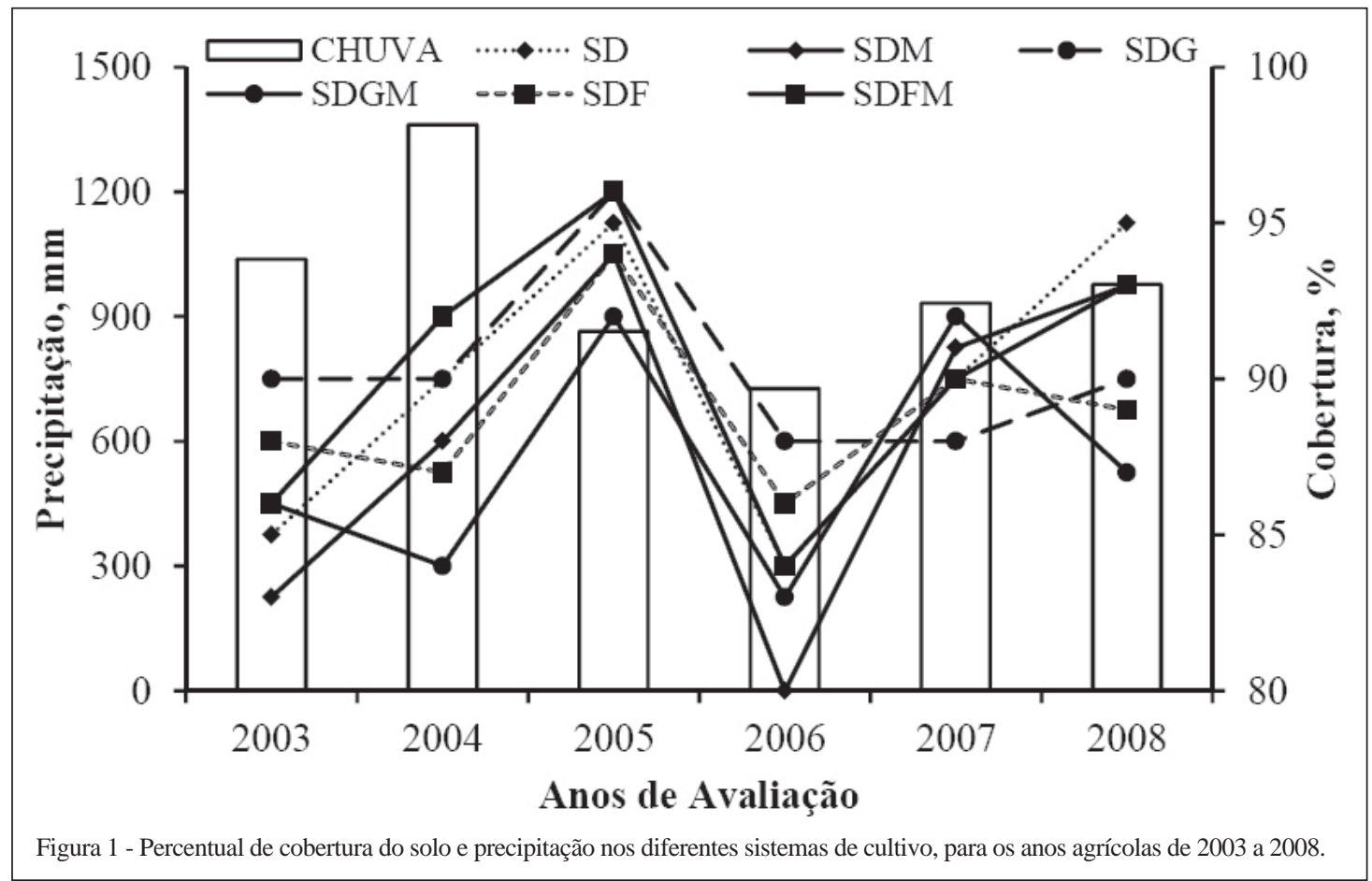

Ciência Rural, v.43, n.9, set, 2013. 
claro que uma boa distribuição das chuvas ao longo dos anos favorece a manutenção dos restos culturais. A importância dessa variável pode ser justificada por regiões tropicais, pelo fato da decomposição dos restos culturais ser muito rápida, devido às condições climáticas e baixa ralação $\mathrm{C} / \mathrm{N}$ das plantas de cobertura do solo (SILVA et al., 1999).

Os tratamentos mostraram, em média, percentuais acima de $80 \%$ (Figura 1), em trabalhos como o de SILVA et al. (2011), avaliando semeadura direta na região nordeste, afirmam que, com o passar dos anos, ocorreu maior aporte de restos culturais na superfície em todos os sistemas avaliados, de forma que, a partir do quarto ano, a percentagem de cobertura ficou próxima dos 100\%. Verificou-se também que essa cobertura do solo manteve-se ao longo dos anos de cultivo com pequenas variações, favorecendo assim os princípios do sistema de semeadura direta, ou seja, com a manutenção da superfície do solo protegida contra os impactos das gotas de chuva, raios solares e mantendo condições adequadas de umidade para o desenvolvimento da cultura e a sua melhor produtividade (SILVA et al., 2011).

De modo geral, a adubação mineral contribuiu para um maior estoque de fitomassa (Tabela 1). A adubação mineral, em especial o fornecimento de $\mathrm{N}$, favorece o desenvolvimento das plantas, contribuindo para o acúmulo de fitomassa sobre a superfície do solo, fato também observado por BAYER et al. (2000). Pode-se notar também que, nos sistemas de cultivo, na ausência de adubação mineral, a inclusão de leguminosas contribuiu para um incremento de fitomassa, sendo mais evidenciado no sistema de cultivo SDM. Também houve acúmulo de fitomassa ao longo dos anos de avaliação. Esses incrementos de fitomassa também são confirmados por NASCIMENTO e SILVA (2004), em avaliação da fitomassa de leguminosas na região Nordeste, os quais concluíram que a fitomassa da mucuna preta teve incrementos ao longo dos três anos de avaliação. O uso da mucuna foi de suma importância para condução da semeadura direta, pois, de acordo com SILVA NETO (2003), o uso de diferentes espécies vegetais usadas na cobertura do solo é fundamental para viabilizar e aumentar a eficiência da semeadura direta. Outro fator importante no acúmulo de fitomassa é a precipitação pluvial, já que os anos com maiores precipitações (2007 e 2008) promoveram maiores acúmulos de fitomassa, com valores em sua grande maioria superiores a $6,00 \mathrm{Mg} \mathrm{ha}^{-1}$.

Na tabela 2, são apresentados os dados de produtividade de grãos de milho nos diferentes

Tabela 1 - Estoque de fitomassa vegetal da parte aérea em diferentes anos de cultivo e sistemas de culturas, na presença e ausência de adubação mineral com N-P-K.

\begin{tabular}{|c|c|c|c|c|c|c|c|}
\hline \multirow{2}{*}{ Ano de Cultivo } & \multirow{2}{*}{ Adubação } & \multicolumn{6}{|c|}{ 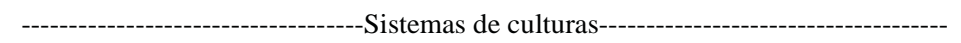 } \\
\hline & & SD & SDM & SDG & SDGM & SDF & SDFM \\
\hline & & \multicolumn{6}{|c|}{---------------------------------------Mg ha' } \\
\hline \multirow{2}{*}{2006} & Não adubado & 3,24 & 4,17 & 3,45 & 3,57 & 5,29 & 3,44 \\
\hline & Adubado & 5,61 & 5,00 & 5,72 & 4,06 & 4,58 & 5,66 \\
\hline \multirow{2}{*}{2007} & Não adubado & 4,45 & 5,78 & 5,01 & 5,55 & 6,12 & 5,98 \\
\hline & Adubado & 6,60 & 9,52 & 6,11 & 6,64 & 8,20 & 5,81 \\
\hline \multirow{3}{*}{2008} & Não adubado & 4,55 & 6,74 & 5,23 & 4,19 & 5,70 & 6,96 \\
\hline & & & & & & & \\
\hline & Adubado & 11,07 & 6,19 & 7,34 & 6,07 & 4,97 & 7,22 \\
\hline \multirow[b]{2}{*}{ Média } & Não adubado & 4,08 & 5,56 & 4,56 & 4,43 & 5,70 & 5,46 \\
\hline & Adubado & 7,76 & 6,90 & 6,39 & 5,59 & 5,91 & 6,23 \\
\hline
\end{tabular}

Semeadura Direta (SD), Semeadura Direta com Mucuna (SDM), Semeadura direta com Guandu (SDG), Semeadura Direta com Guandu e Mucuna (SDGM), Semeadura Direta com Fava (SDF), Semeadura Direta com Fava e Mucuna (SDFM). 
Tabela 2 - Média de Produtividade de grãos de milho nos diferentes sistemas de culturas, na presença e ausência de adubação mineral com N-P-K durante nove anos.

\begin{tabular}{|c|c|c|c|c|c|c|}
\hline \multirow{2}{*}{ Adubação } & \multicolumn{6}{|c|}{ - } \\
\hline & SD & SDM & SDG & SDGM & SDF & SDFM \\
\hline Não adubado & $3,447 \mathrm{bAB} *$ & $3,728 \mathrm{bAB}$ & $3,226 b B$ & $3,425 \mathrm{bAB}$ & 3,399bB & $4,000 \mathrm{bA}$ \\
\hline Adubado & $5,063 \mathrm{aAB}$ & $5,047 \mathrm{aAB}$ & $4,665 \mathrm{aB}$ & $4,849 \mathrm{aA}$ & $5,074 \mathrm{aA}$ & 4,884aA \\
\hline
\end{tabular}

*Letras minúsculas iguais na coluna e maiúsculas na linha não diferem estatisticamente em nível de 1\%, por Tukey.

Semeadura Direta (SD), Semeadura Direta com Mucuna (SDM), Semeadura direta com Guandu (SDG), Semeadura Direta com Guandu.

sistemas de culturas. Na ausência de adubação, o sistema mais produtivo foi semeadura direta + fava + mucuna (SDFM), diferindo estatisticamente dos sistemas semeadura direta com guandu (SDG) e com fava (SDF), sem a presença da mucuna. A inclusão de leguminosas apresenta-se como boa alternativa de ciclar nutrientes e aumentar a produtividade do milho. Isso se dá por que, segundo NASCIMENTO e SILVA (2003), sistemas de produção envolvendo leguminosas para cobertura de solo podem substituir parcial ou totalmente a adubação nitrogenada de cobertura, sem perda no rendimento de grãos de milho. Isso é possível porque as leguminosas adicionam nitrogênio ao sistema. Por outro lado, CUNHA et al. (2011a) não obtiveram diferenças no rendimento do milho, em semeadura direta com mucuna, num Latossolo em Goiás.

Quando se compara o uso da adubação mineral nos sistemas de culturas (Tabela 2), observase que sua presença promove aumento no rendimento de grãos de milho. Entretanto, esse incremento é sempre maior na ausência da mucuna preta, pois a diferença de $1,62 \mathrm{Mg} \mathrm{ha}^{-1}$ na SD decresce para $1,32 \mathrm{Mg} \mathrm{ha}^{-1}$ na SDM e de $1,68 \mathrm{Mg} \mathrm{ha}^{-1}$ na SDF para $0,88 \mathrm{Mg} \mathrm{ha}^{-1}$ na SDFM, o que comprova a eficiência da mucuna em aumentar o rendimento da cultura principal. CUNHA et al. (2011b) observaram que a mucuna teve ação positiva na fitomassa, o que indica maior quantidade de matéria orgânica ativa no solo, capaz de manter elevada a taxa de decomposição de resíduos vegetais e de ciclar mais nutrientes.

Pode-se observar que os maiores valores de produtividade de milho ocorrem em função da quantidade e distribuição da precipitação pluvial (Figura 2). Nos anos de 2002 e 2007, os baixos valores de produtividade podem ser explicados pela má distribuição das chuvas, com veranicos no período de florescimento, apesar da precipitação acima de 600mm. Para HALL et al. (1982) e RAKIR (2004), a influência da precipitação na produtividade está muito mais relacionada com a época em que ocorre e com a distribuição das chuvas durante o ciclo da cultura. Isso acontece devido às necessidades hídricas e a sensibilidade a estresse diferente em cada fase fenológica.

Comparando os anos avaliados, o melhor ano foi o de 2008, destacando-se dos demais, com diferença significativa, obtendo valores de produtividade superiores a $6,5 \mathrm{Mg} \mathrm{ha}^{-1}$ (Figura 2). A boa distribuição das chuvas durante as fases do ciclo fenológico da cultura do milho, nesse ano, pode ter favorecido o desenvolvimento da cultura e, consequentemente, uma boa formação e enchimento de grãos de milho. De acordo com SILVA et al. (2011), a boa distribuição da precipitação pluvial, além da quantidade precipitada, é de fundamental importância para produtividade em agricultura de sequeiro, na região Nordeste.

\section{CONCLUSÃO}

O percentual de cobertura e o acúmulo de fitomassa no solo aumentam com o passar dos anos de cultivo em sistemas de semeadura direta e são influenciados positivamente pela precipitação pluvial, adubação mineral e uso de plantas de cobertura leguminosas. A presença de adubação mineral proporcionou maiores valores de produtividade de grãos de milho para todos os sistemas de cultivo, mas aqueles com a presença da mucuna preta obtiveram melhor desempenho e, embora a precipitação pluvial seja um fator limitante para acumular fitomassa seca sobre a superfície do solo, a utilização de mucuna preta nos sistemas de culturas contribuiu para incrementar a produção de fitomassa e facilitar a implantação da semeadura direta na região. 



Figura 2 - Precipitação e média de produtividade de milho para os nove anos agrícolas de 2000 a 2008, nos diferentes sistemas de cultivo: (a) SD e SDM; (b) SDG e SDGM e (c) SDF e SDFM, 


\section{REFERÊNCIAS}

BAYER, C. et al. Efeito de sistemas de preparo e de cultura na dinâmica da matéria orgânica e na mitigação das emissões de $\mathrm{CO}_{2}$. Revista Brasileira de Ciência do Solo, v.24, p.599607, 2000. Disponível em: <http://redalyc.uaemex.mx/redalyc/ pdf/1802/180218342013.pdf.> Acesso em: 26 abr. 2012.

CUNHA, E. de Q. et al. Sistemas de preparo do solo e culturas de cobertura na produção orgânica de feijão e milho. I - Atributos físicos do solo. Revista Brasileira de Ciência do Solo, v.35, n.2, p.603-611, 2011a. Disponível em: <http://www.scielo.br/ scielo.php?pid=S0100-06832011000200028\&script=sci_arttext $>$. Acesso: 26 abr. 2012. doi:10.1590/S0100-06832011000200028.

CUNHA, E. de Q. et al. Sistemas de preparo do solo e culturas de cobertura na produção orgânica de feijão e milho. II - Atributos biológicos do solo. Revista Brasileira de Ciência do Solo, v.35, n.2, p.603-611, 2011b. Disponível em: <http://www.scielo. br/scielo.php?pid=S0100-06832011000200029\&script $=$ sci arttext>. Acesso em: 26 abr. 2012. doi:10.1590/S0100-0683201 1000200029

EMPRESA BRASILEIRA DE PESQUISA AGROPECUÁRIA (EMBRAPA). Sistema brasileiro de classificação de solos. 2.ed. Brasília: EMBRAPA Produção de informação; EMBRAPA Solos, 2006. 306p.

FRAGA, V. da S. Mudanças na matéria orgânica (C, N e P) de solos sob agricultura de subsistência. 2002. $76 f$ Tese (Doutorado em Solos) - Programa de Pós-graduação em Tecnologias Energéticas e Nucleares, Universidade Federal de Pernambuco,.

HALL, A.J. et al. The effects of water stress and genotype on the dynamics of pollen-shedding and silking in maize. Field Crops Research, v.5, p.349-363, 1982. Disponível em: <http:// www.sciencedirect.com/science/article/pii/0378429082900363>. Acesso em: 26 abr. 2012. doi:10.1016/0378-4290(82)90036-3.

NASCIMENTO, J.T; SILVA, I.F. Avaliação quantitativa e qualitativa da fitomassa de leguminosas para uso como cobertura de solo. Ciência Rural, v.34, n.3, p.947-949, 2004. Disponível em: <http://www.scielo.br/pdf/cr/v34n3/a47v34n3.pdf.> Acesso em: 26 abr. 2012

NUNES, H.V. et al. Decomposição de restos culturais dispostos na superfície do solo e submetidos a adubação nitrogenada na microrregião de Guarabira-PB. Acta Tecnológica, v.5, n.1, p.1730, 2010. Disponível em: <http://portaldeperiodicos.ifma.edu.br/ index.php/actatecnologica/article/view/18/15>. Acesso em: 26 abr. 2012.

PAVINATO, P.S. et al. Disponibilidade de cátions no solo alterada pelo sistema de manejo. Revista Brasileira de Ciência do Solo, v.33, n.4, p.1031-1040, 2009. Disponível em: <http://www.scielo. br/scielo.php?pid=S0100-06832009000400027\&script $=$ sci arttext>. Acesso em: 26 abr. 2012. doi: 10.1590/S010006832009000400027.

RAKIR, R. Effect of water stress at different development stages on vegetative and reproductive growth of corn. Field Crops Research, v.89, n.1, p.1-16, 2004. Disponível em: <http:// www.mendeley.com/research/effect-water-stress-differentdevelopment-stages-vegetative-reproductive-growth-corn-14/> . Acesso em: 26 abr. 2012. doi: 10.1016/j.fcr.2004.01.005.

SILVA, L.S. et al. Efeito da rotação de culturas, adubação verde e nitrogenada sobre o rendimento do feijão. Pesquisa Agropecuária Brasileira, v.34, n.11, p.2029-2036, 1999. Disponível: <http:// www.fapese.org.br/revista_fapese/v4n2/artigo11.pdf $>$. Acesso em: 22 abr. 2012

SILVA, A.S. et al. Semeadura direta na produção do milho em agricultura de sequeiro na região Nordeste do Brasil. Ciência Rural, v.41, n.9, p.1556-1562, 2011. Disponível em: <http://www. scielo.br/scielo.php?pid=S0103-84782011000900011\&script=sci_ arttext>. Acesso em: 26 abr. 2012. doi: 10.1590/S010384782011000900011 .

SILVA NETO, L.F. Influência do plantio direto e da cobertura vegetal sobre os atributos físicos e matéria orgânica do solo e produtividade do milho. 2003. 41f. Monografia (Graudação em Agronomia) - Centro de Ciências Agrárias, Universidade Federal da Paraíba, PB.

SIQUEIRA NETO, M. et al. Rotação de culturas no sistema plantio direto em Tibagi (PR). I - Sequestro de carbono no solo. Revista Brasileira de Ciência Solo, v.33, n4, p.1013-1022, 2009. Disponível em: <http://www.scielo.br/scielo.php?pid=S010006832009000400026\&script=sci_arttext $>$. Acesso em: 26 abr. 2012. doi: 10.1590/S0100-06832009000400026.

SLONEKER, L.L.; MOLDENHAUER, W.C. Measuring the amounts of crop residue remaining after tillage. Journal of Soil and Water Conservation, v.32, p.231-236, 1977. 